Felipe C. O. de Mello \& Marco Schneider

\title{
Desinformação Digital em Rede e Competência Crítica em Informação
}

\section{Networked Digital Disinformation and Critical Information}

\section{Resumo:}

A noção contemporânea de desinformação guarda alguma semelhança com o conceito agostiniano de mentira, pois traz consigo a intenção de enganar. Hoje como outrora, diversas formas de logro deliberado reforçam ilusões e preconceitos, dado que a cognição humana é ludibriável. A novidade está no impacto social resultante da imensa capacidade de captura, processamento e circulação de dados das atuais mediações sócio técnicas da informação, que operam na escala do big data e cujo alcance, velocidade e capilaridade fazem da desinformação digital em rede um fenômeno inédito e alarmante. A promoção da competência crítica em informação, que envolve o amadurecimento do senso crítico, surge como um meio crucial para atenuar o problema.

Palavras-chave: Desinformação, Mentira, Desinformação Digital em Rede, Competência Crítica em Informação

\begin{abstract}
:
The contemporary notion of disinformation bears some resemblance to the Augustinian concept of lying, as it carries with it the intention to deceive. Today, as in the past, several forms of deliberate deception reinforce illusions and prejudices, given that human cognition is deceptive. The novelty is the social impact resulting from the immense capacity for capturing, processing and circulating data of current sociotechnical mediations of information, which operate on the big data scale and whose reach, speed and capillarity make digital network disinformation an unprecedented and alarming phenomenon. The promotion of critical information literacy, which involves the maturation of critical sense, appears as a crucial means to mitigate the problem.
\end{abstract}

Keywords: Critical Information Literacy, Disinformation, Digital Network Disinformation, Lie.

\section{Agenda:}

1. Introdução

2. Desinformação, Mentira e Desinformação Digital em Rede..................................................... 3

3. Senso Crítico, Honestidade Intelectual e Competência Crítica em Informação ........................ 6

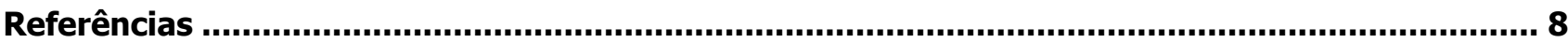

\section{Authors:}

Felipe C. O. de Mello

- Universidade Federal do Rio de Janeiro - Biblioteca Paulo Geyer (Escola de Química) - Av. Athos da Silveira Ramos, 149 - sala E210 - Cidade Universitária, 21941-590, Rio de Janeiro - RJ, Brasil.

- $₫$ felipemello@eq.ufrj.brl, 믈 http://lattes.cnpq.br/9502376814545409

Prof. Dr. Marco Schneider:

- Instituto Brasileiro de Informação em Ciência e Tecnologia, Rua Lauro Müller, 455, 40 andar, Botafogo, 22290-160, Rio de Janeiro - RJ, Brasil.

- Universidade Federal Fluminense, Rua Lara Vilela, 126, São Domingos, 24210-590, Niterói - RJ, Brasil; Bolsista do CNPq e da Faperj.

- $\triangle$ marcoschneider@ibict.br, 昌 http://lattes.cnpq.br/6589062304969432 


\section{Introdução}

Temendo mais o isolamento do que o erro, compartilhavam das

opiniões da maioria

(qtd. in Noelle-Neumann 67)

O ser humano é ludibriável e suas crenças pessoais podem interferir em seu raciocínio. Segundo Seth, "a percepção nunca é uma janela direta para uma realidade objetiva" (Seth 29). Para Wardle, os indivíduos são programados para responderem a gatilhos emocionais, de modo que são levados a compartilhar informações falsas, desde que isso reforce suas crenças e preconceitos preexistentes ("Uma Nova Desordem Mundial" 46). Outro fator que pode reforçar o compartilhamento de informações falsas é a dissonância cognitiva, um estado desconfortável que o sujeito sente quando suas crenças conflitam com crenças diferentes, ou quando evidências factuais e observáveis vão de encontro às suas convicções. Quando isso ocorre, as pessoas procuram reduzir o efeito desconfortável da dissonância cognitiva, racionalizando o conflito gerado, de modo que tal conflito passe a fazer sentido para a crença do indivíduo (Van Bavel e Pereira 215-216).

Observando tal situação, há de se considerar que as pessoas frequentemente tendem a não ser "boas avaliadoras de razões, especialmente quando refletem sobre ideias que lhes são caras", pois estão sujeitas "à influência de uma série de vieses cognitivos [...] em grande medida fora de nossa atenção consciente" (Guzzo e Lima 3-4).

Vale a pena mencionar aqui dois vieses cognitivos, relacionados de modo circular: o viés do raciocínio motivado e o viés de confirmação. Ambos estão ligados à questão da dissonância cognitiva. $O$ viés do raciocínio motivado busca razões plausíveis para justificar uma crença, fazendo com que as pessoas acessem, construam e avaliem discussões e dados de modo enviesado, obtendo uma conclusão preferida, enquanto o viés de confirmação faz com que evitem informações que ameacem o seu bem-estar e felicidade, induzindo-as a buscar informações que ratifiquem suas crenças (Guzzo e Lima 6-7; Ética Animal; Froehlich).

Além da crença, a pressão social é outro fator que influencia o compartilhamento de desinformações. Em 1955, o psicólogo social Solomon E. Asch publicou um artigo no periódico Scientific American, onde foi relatado um experimento com alguns universitários. Lhes foi pedido que comparassem o comprimento de linhas desenhadas em cartões com uma linha de referência. Eles deveriam dizer quais das linhas eram iguais à de referência. Foi combinado com a maioria que, em determinado momento, eles passariam a escolher a linha errada, e o sujeito foco do estudo não foi informado disso. A medida em que o experimento seguia, os outros participantes começaram a ter uma opinião unânime, escolhendo sempre a linha errada. Isso deixou o sujeito foco desconfortável, pois havia sobre ele duas forças opostas: a evidência de seus sentidos visuais e a opinião unânime da maioria. Além disso, o sujeito foco deveria declarar perante todos a sua posição. Na maior parte dos casos descritos no experimento de Asch, os sujeitos-foco concordavam publicamente com a opinião da maioria, sendo poucos aqueles que se mantiveram firmes em sua posição (Asch 3). Ao que parece, o medo do isolamento social tende a levar o sujeito a concordar com a visão majoritária, mesmo que ela contrarie sua percepção. Uma opinião majoritária pode gerar insegurança no indivíduo que pensa diferente. O problema que se coloca é que se algum consenso é indispensável para a vida social, o conformismo pode levar as pessoas a renunciarem ao próprio discernimento (Asch 5).

Heller também faz uma importante distinção entre conformidade e conformismo, numa linha de raciocínio semelhante à de Asch, argumentando que se a conformidade é em certa medida indispensável à vida cotidiana, dado que esta seria inviável se exigisse a cada instante reflexões e ações elaboradas e inovadoras, o conformismo as bloqueia quando seriam necessárias: na ciência, na arte, na política. Assim, um dos perigos da propensão psicológica conformista a diminuir o desconforto da insegurança pode conduzir as pessoas ao alinhamento com ideias absurdas e líderes autoritários, "em busca de ideologias e visões de mundo que celebrem o mito de um passado glorioso", de modo que o sujeito se sinta confortável novamente com a homogeneidade de pensamento, se alegrando "com a liberdade de acessar apenas informações que confirmem quem são, ou quem gostariam de ser" (Hogg 44). 
A rede mundial de computadores, de modo paradoxal, promove uma diversidade de "pensamentos majoritários", que acabam produzindo bolhas informacionais e polarizações, cristalizando preconceitos. Esse encontro "polarizante" entre pensamentos majoritários pode, de certo modo, deixar o senso de identidade de alguns ameaçado, gerando incerteza. Portanto, na sua necessidade de se ver protegido de conflitos, e no seu anseio de obter confirmação de ações anteriores, o indivíduo se firma na crença de seus preconceitos (Heller 75).

Antes da popularização da internet, já anunciava um famoso comercial de TV da Folha de São Paulo: "é possível contar um monte de mentiras, dizendo só a verdade" (W/Brasil 00:00:43-00:00:48). O anúncio começa com uma imagem indefinida, composta de pontos pretos dispersos em fundo branco, que vão gradualmente se organizando e ganhando definição, enquanto uma voz em off descreve aparentes grandes feitos de um estadista, sem nomeá-lo. Em dado momento, forma-se a imagem de Hitler e o anúncio encerra com a ideia de que é possível mentir só dizendo verdades e que é necessário ficarmos alertas.

A conclusão faz lembrar a célebre sentença hegeliana, de que a verdade está no todo. Ou seja, no caso do comercial, a imagem de Hitler enfim aparece e as notórias calamidades associadas a essa imagem, de conhecimento comum, são forçosamente confrontadas com as impressões positivas que as verdades parciais de seus feitos induziam, sem que soubéssemos de quem se tratava. Ao fim, o confronto conduz à desconstrução da imagem positiva que inicialmente se criara antes do fecho (ou assim se espera). No final, a verdade se estabelece a partir do ponto de vista da totalidade.

Nessa linha, é admissível parafrasear Hegel e dizer que a mentira também está no todo, mas no todo incompleto e farsesco que se apresenta como o real, visto que mesmo uma narrativa composta somente de verdades, mas que deixa de fora outras verdades necessárias para a compreensão adequada de uma dada situação, ou que fragmenta, descontextualiza e mistura verdades, pode ser uma narrativa mentirosa.

Fato é que embora recorram com frequência à mentira pura e simples, no sentido de informação ou narrativa incorreta em relação a fatos e causas, as práticas desinformativas não se resumem a difusão de mentiras, embora desinformar seja o mesmo que mentir, ainda que se possa desinformar comunicando somente verdades, mediante a ocultação de informação relevante, circulação intensiva de informação irrelevante, descontextualização informativa, anacronismos, mistura de fatos reais com ficção etc. Pode-se, portanto, desinformar / mentir inclusive só dizendo ou mostrando verdades, integralmente ou parcialmente, ontem e hoje, nas redes digitais e fora delas.

Entretanto, é no ambiente ubíquo das redes digitais, onde diversas opiniões majoritárias - cheias de certezas e preconceitos, frequentemente recheadas de absurdos ficcionais apresentados como fatuais - são proferidas e compartilhadas compulsivamente, que a desinformação digital em rede se espalha de modo mais rápido, mobilizando corações e mentes, convertendo-se então em infodemia, quando a escala e os efeitos deletérios da desinformação passam a ser comparados com os de uma epidemia.

\section{Desinformação, Mentira e Desinformação Digital em Rede}

Segundo Posetti e Matthews, "misinformation1, desinformação e propaganda têm sido características da comunicação humana" desde tempos antigos, havendo registros já na época do Império Romano (1). Entretanto, a desinformação ganhou um poder de disseminação maior graças aos avanços tecnológicos. Com a popularização "da internet no final do século XX, seguida pelas mídias sociais no século XXI, os riscos de misinformation, desinformação, propaganda e boatos, se multiplicaram dramaticamente" (Posetti e Matthews

\footnotetext{
1 Misinformation é informação errada ou inexata, posta em circulação sem intenção de dolo. Como não há tradução acadêmica consagrada em português para o termo, optou-se por mantê-lo em inglês.
} 
1). Como exemplo disso, cita-se a pesquisa realizada pela União Pró-Vacina ${ }^{2}$ (UPVacina) em 2020, que revelou um aumento de $383 \%$ em postagens com desinformação relacionada à vacina contra a Covid-19 no Brasil, entre o período de $1^{\circ}$ de maio a 31 de julho de 2020. Além disso, vale citar que o algoritmo do Facebook agiu como facilitador de disseminação de desinformação sobre saúde em outros cinco países - Estados Unidos, Reino Unido, França, Alemanha e Itália - fazendo com que postagens com informações falsas alcançassem 3,8 bilhões de acessos entre 2019 e 2020 (Moreira; Cardoso; AVAAZ). Há de se considerar que o problema da desinformação também é potencializado na contemporaneidade, ao se perceber que a desinformação pode ser um negócio lucrativo para aqueles que a disseminam propositalmente. Segundo estudo do Global Disinformation Index (GDI), que analisou a presença de propagandas on-line em 20 mil domínios web dedicados a espalhar desinformação, o mercado da desinformação movimenta, estimativamente, por volta de US $\$ 235$ milhões por ano para os domínios analisados, utilizando-se de publicidade programática, uma espécie de leilão automático de espaços publicitários em sites em tempo real. Ainda conforme o relatório do GDI, a propaganda digital superará a tradicional por volta do ano de 2021 e empresas que desenvolvem tecnologias de publicidade programática deverão lidar com o risco de anúncios pararem em sites que procuram desinformar (Global Disinformation Index Staff 5).

Desinformação é informação falsa, inexata ou enganosa, produzida com a intenção de provocar prejuízo público, social ou científico. Envolve um conjunto de ações intencionais que constroem cenários determinados, no intuito de moldar a opinião pública de acordo com o interesse de quem a produz, geralmente se utilizando de mecanismos para descontextualizar, fragmentar, manipular, distorcer fatos, tendo por objetivos o ganho financeiro; a influência política, tanto no país quanto no estrangeiro; ou o simples prazer de causar problemas (Brisola e Bezerra 3319 e 3323; Directorate-General for Communications Networks 10; Wardle, "Uma Nova Desordem Mundial" 48). ${ }^{3}$

Curiosamente, essa definição de desinformação é similar ao conceito de mentira de Santo Agostinho. Segundo o filósofo,

[...] o mentiroso tem um coração duplo, isto é, um pensamento ramificado: um que, conhecendo ou sentindo [em seu espírito] qual é a verdade de fato, não se pronuncia, e outro que, mesmo conhecendo ou sentindo [que não é verdade], ainda assim, profere o que é falso. [...] A culpa do mentiroso está em seu desejo intencional de enganar (Santo Agostinho 18).

Santo Agostinho ainda afirma que "ninguém pode duvidar de que mente aquele que deliberadamente diz uma coisa falsa com intenção de enganar. Portanto, dizer uma coisa falsa com intenção de enganar é uma mentira declarada" (Santo Agostinho 21). Talvez, em termos agostinianos, possa-se afirmar que desinformação equivale a mentira.

No entanto, Agostinho também afirma que nem todo aquele que diz algo falso é necessariamente mentiroso:

Quem expressa o que crê interiormente, ou guarda em seu pensamento aquilo que supõe, ainda que isso seja falso, não mente. Pois acredita [ser verdade] o que declara a sua fé, e, impulsionado por essa crença, a expressa conforme o que ele sente. No entanto, não ficará sem culpa, ainda que não minta,

\footnotetext{
2 "A União Pró-Vacina é uma iniciativa organizada pelo Instituto de Estudos Avançados (IEA) Polo Ribeirão Preto da USP em parceria com o Centro de Terapia Celular (CTC), o Centro de Pesquisa em Doenças Inflamatórias (CRID), os projetos de divulgação científica Ilha do Conhecimento e Vidya Academics e o Gaming Club da FEA-RP". Tem por objetivo reunir instituições acadêmicas e de pesquisa, poder público, além de órgãos e institutos da sociedade civil "para combater a desinformação sobre vacinas, planejando e coordenando atividades conjuntas durante todo o ano de 2020, explorando as potencialidades de cada instituição participante" (Instituto de Estudos Avançados - Polo Ribeirão Preto).

${ }^{3}$ Registre-se que outros autores (cf. Brito e Pinheiro) distinguem desinformação em um sentido geral, que se aproxima do que estamos empregando aqui, mas que engloba a noção de misinformation ou desinformação não intencional, e desinformação em um sentido restrito, como pura e simples mentira deliberada. Para evitar confusão, optamos neste artigo por não entrar nesses meandros conceituais, não obstante reconheçamos sua importância para investigações mais longas ou de recorte distinto.
} 
se acredita no que não deve acreditar, ou imagina que sabe o que na realidade ignora (Santo Agostinho 18).

Para o filósofo, a mentira existe na intenção de quem a enuncia. Assim, aquele que diz algo falso, mas acredita nessa falsidade, não mente quando a compartilha. Informações falsas, compartilhadas sem a intencionalidade do engano, são chamadas de chamada misinformation, "se resultadas de um erro honesto, negligência, viés inconsciente" (Fallis 136). Froehlich (" $A$ not-so-brief') determina que a diferença entre desinformação e misinformation é a intencionalidade do engano. Segundo Wardle e Derakshan (20), misinformation é uma informação falsa, porém não criada com intenção de causar prejuízo. Os indivíduos que compartilham misinformation, por não saberem que uma parte da informação - ou toda a informação - é falsa, a compartilham nas mídias sociais, acreditando que, ao fazerem isso, estarão ajudando a outros (Wardle, "Information Disorder"). Porém, como diz o ditado popular, de boas intenções o inferno está cheio, de modo que mesmo sem querer, pode-se provocar muito estrago. Pois mesmo que o sujeito não minta, no sentido agostiniano, ao compartilhar informação enganosa ele aumenta sua potência destrutiva, sobretudo quando esse compartilhamento é mediado pelas redes digitais, cujo alcance potencial pode gerar um "comportamento de manada", "tendência das pessoas de seguirem um grande influenciador ou mesmo um determinado grupo, sem que a decisão passe, necessariamente, por uma reflexão individual" (Gragnani). As fake news são uma modalidade de desinformação que tira proveito desse comportamento de manada.

Para Allcott e Gentzkow (214), fake news não dizem respeito a erros jornalísticos não intencionais; a rumores que não possuem origem em uma fonte de notícia específica (boatos); a teorias da conspiração, sátiras, falsos testemunhos de políticos ou a relatórios - não totalmente falsos - que possuam alguma espécie de inclinação para interesse de terceiros. Esses dois pesquisadores irão definir fake news como "artigos de notícias que são intencionalmente e verificadamente falsos, e que podem enganar os seus leitores (Allcott e Gentzkow 213). Brisola e Bezerra (3323) complementam esta definição: [fake news] "são notícias fabricadas, com características jornalísticas, mas antecipadamente pensadas para a manipulação e descoladas da verdade".

Fake news não são, portanto, sinônimo de desinformação, mas uma modalidade desinformacional. Brisola e Bezerra (3324) alertam para a importância dessa distinção, no sentido de orientar "ações de coibição ou resistência a cada um dos fenômenos". Acrescentamos que a especificidade do fenômeno recente das fake news decorre do fato de se constituírem numa modalidade de desinformação digital em rede, embora notícias falsas ou imprecisas tenham sempre estado presentes em mídias convencionais. A diferença é que novas mediações e mediadores entram em cena na ambiência das redes digitais e em seu intercurso com as mídias convencionais, contribuindo decisivamente para a produção do efeito desinformacional que vem sendo chamado de infodemia, neologismo que designa circulação de desinformação em enorme escala, gerando efeitos sócio ambientais deletérios: na política, com a emergência de neofascismos; na saúde pública, com os movimentos antivacina e anticiência em geral; no meio ambiente, com o negacionismo climático, entre outros.

Retomando a relação entre desinformação e misinformation, se o potencial destrutivo da primeira é ampliado pela última, como visto, acrescentamos que essa ampliação se deve não só ao fator quantitativo da propagação, mas também ao qualitativo, talvez principalmente a este, se considerarmos que a informação inexata compartilhada entre pessoas que gozam de credibilidade umas em relações às outras - grupos familiares, amigos, correligionários etc. - amplia seu poder de convencimento e raio de alcance, numa espiral viciosa centrífuga. Em outras palavras, a misinformation fortalece a desinformação, ao ampliar a escala da circulação e a intensidade persuasiva da informação oriunda de fontes desinformadoras, confirmando crenças e preconceitos, alertando para algum perigo ilusório, ativando o comportamento de manada na sociedade. Considerando que todos os seres humanos são passíveis de serem enganados - propositalmente com desinformações, acidentalmente com misinformations, ou com a combinação de ambas -, pergunta-se o que se deve fazer para combater infodemias. 


\section{Senso Crítico, Honestidade Intelectual e Competência Crítica em Informação}

Embora seja dificilmente concebível uma solução definitiva aos problemas elencados, pode-se pensar em meios para atenuá-los. Um desses meios seria a promoção do amadurecimento do senso crítico que todos possuem, de modo mais ou menos latente.

Numa primeira formulação, o senso crítico pode ser considerado como o fator cognitivo que permite ao indivíduo ter um conhecimento mais apurado a respeito de suas próprias necessidades informacionais em meio a um mundo caótico de informações. Este senso, que orienta a pessoa em sua atenção e seleção informacional, pode ser amadurecido por meio do pensamento reflexivo e por meio do gosto pelo conhecimento qualificado. Porém, mesmo que o pensamento reflexivo leve o indivíduo a um estado de questionamento e curiosidade, induzindo-o a buscar melhores respostas que gerarão novas e melhores perguntas - e, por consequência, novos e melhores conhecimentos (Bezerra, Schneider e Brisola 8-9) -, o próprio pensamento reflexivo sofre influência do meio. Por isso Gasque (60) afirma que a reflexão pode gerar erros e enganos, se a pessoa que se guia pela razão estiver cega por sua própria cultura - que envolve suas crenças e preconceitos -, ou quando o indivíduo não tem uma "visão ampla e compreensiva do todo". Por isso, a "honestidade intelectual é absolutamente indispensável para que não sejamos vítimas de nossas tendências naturais" (Rodrigues), pois essa honestidade exigirá um exame consciente da reflexão interna para com a informação externa que é acessada. Introduzimos assim, com a noção de honestidade intelectual, a conexão necessária entre senso crítico, pensamento reflexivo e ética em informação, não a partir de meras boas intenções, mas da própria lógica imanente de amadurecimento do senso crítico.

Honestidade intelectual envolve autocrítica. Vem, portanto, atrelada à prudência, entendida no sentido empregado por Capurro ("Desafios"), como "o horizonte de alguém que é consciente de seus limites [...] e evita que busquemos soluções simplistas". Capurro ("Desafios") acrescenta que "uma reflexão ética prudente tem também como função a de despertar e preservar a sensibilidade ética", além de ter o dever de "pensar o universal sem deixar de lado a singularidade de formas de vida e os fatos históricos e geográficos".

Em um mundo deslumbrado e assombrado por uma cacofonia de absurdos, o senso crítico amadurecido pode ser pensado como um dispositivo de mixagem, por assim dizer, permitindo ao indivíduo ser mais criterioso na seleção, avaliação e composição significante das informações que estão ao seu redor:

Grandes pensadores não apenas assumem sistematicamente o comando de seus pensamentos, mas também monitoram, revisam e repensam, continuamente, estratégias para o aprimoramento contínuo do seu pensar. Eles internalizaram profundamente as habilidades básicas do entendimento, de modo que o pensamento crítico para eles é tanto consciente quanto altamente intuitivo. Como Piaget colocaria, eles regularmente elevam seus pensamentos para o nível de realização consciente. Através de extensiva experiência e prática na dedicação de se auto avaliar, grandes pensadores não apenas analisam ativamente seus pensamentos em todos os domínios significativos de suas vidas, mas também desenvolvem continuamente novos insights sobre problemas em profundos níveis mentais. Grandes pensadores estão profundamente comprometidos com a honestidade intelectual e possuem um alto nível de controle, embora não perfeito, de suas naturezas egocêntricas (Elder; Paul).

Partindo da premissa de que o senso crítico amadurecido está potencialmente ao alcance de todos, sua promoção torna-se mais do que nunca uma emergência, diante do colapso intelectual e socioambiental em curso. Pois o indivíduo que amadurece o senso crítico tende a perceber com mais clareza sua responsabilidade para com o conjunto dos seus semelhantes. O semelhante aqui mencionado não se refere exclusivamente a um indivíduo que pertence a uma mesma classe social ou a um mesmo povo ou cultura, mas ao semelhante no gênero humano. Eagleton escreve que

[...] encontrarmo-nos uns com os outros puramente como corpos companheiros é tão palpável quanto abstrato. Visto que carne e osso são aquilo que nos constitui, a universalidade da espécie entra em cada 
vez que respiramos, em cada gesto que fazemos [...] o perto e o longe se aliam, pelo menos no sentido de que o próximo é, simplesmente, qualquer estranho que porventura tenha vindo parar na nossa presença (Eagleton 428).

Portanto, constata-se que, fundamentalmente, nenhum indivíduo está sozinho no mundo, e que o outro nunca é um objeto destituído de personalidade, vontades e deveres. "Uma pessoa é uma pessoa através de outras pessoas" (qtd. in Olinger, Britz e Oliver 5). Assim, o florescimento mais pleno da própria individualidade só pode se dar no âmbito do coletivo e da colaboração, deslocando a competição inevitável entre humanos de sua posição dominante na cultura contemporânea (Schneider 112). Por essa via, pessoas que amadurecem o senso crítico, que envolve um alto nível de autoconhecimento, devem auxiliar aqueles sujeitos que ainda não compreendem "as tarefas de seu tempo" - tarefas estas que são "apresentadas por uma 'elite' que as interpreta e lhas ( sic) entrega em forma de receita, de prescrição a ser seguida" - a se enxergarem como sujeitos, e não como objetos massificados, domesticados e desesperançados (Freire 51). O sujeito de senso crítico amadurecido deve, de algum modo, estimular em seu semelhante o mesmo amadurecimento, uma atitude crítica permanente, sem ignorar, no entanto, o contexto político, cultural e social daquele que está disposto a aprender (Bezerra, Schneider e Brisola 11), nem perder de vista que "é difícil, senão impossível, remover mediante palavras hábitos há longo tempo incorporados ao caráter dessas pessoas" (Aristóteles, 316). Em outros termos, não se apresenta aqui uma visão ingênua, dicotômica e hierárquica do tipo positivista, que separa inflexivelmente ciência de senso comum e defende a superação deste pela difusão daquela. Diferentemente, sem recusar a priori toda e qualquer hierarquia de pensamentos, o plano consiste em promover no senso comum a sistematização, maturação e atualização de hábitos de pensamento que já se encontram nele presentes, geralmente em estado latente e assistemático. No campo informacional, as noções de senso crítico e pensamento reflexivo aproximam-se do conceito de competência crítica em informação, que agrega ao debate em torno da competência em informação, tradicionalmente marcada por um caráter mais profissional e instrumental, o elemento crítico reflexivo e o compromisso ético-político com a emancipação das classes e minorias sociais exploradas, oprimidas, perseguidas, desfavorecidas.

O ser humano, apesar de toda a complexidade potencial do seu intelecto, é suscetível a falhas de percepção, análise e avaliação, de si mesmo e do mundo objetivo que o cerca, assim como é vulnerável a opiniões, ideias e ideais que confirmem sua visão pessoal a respeito da vida. Crenças e preconceitos, que permeiam os pensamentos e afetos, geram vieses cognitivos, que podem agir como armadilhas do entendimento, levando a pessoa a acreditar e a compartilhar desinformação. Ao que parece, a desinformação é construída com o intuito de afetar o emocional das pessoas, pois é mais na emoção do que na razão que ela encontra abrigo. Logo, a conscientização de tais vulnerabilidades justifica a necessidade do desenvolvimento e do amadurecimento do senso crítico. Porém, para que haja tal amadurecimento, é necessário prática e um constante exercício, que deve ser incentivado e promovido em escala social, mediante políticas públicas de educação crítica para as mídias e da competência crítica em informação. Deve-se ter em mente que nem todo indivíduo estará imediatamente aberto ao pensamento crítico-reflexivo. Quando a crença pessoal de alguém é abalada por uma ideia diferente daquela com a qual se estava acostumado, um sentimento desconfortável de insegurança se instala. "Como um terremoto que confunde a nossa confiança no próprio solo que estamos pisando, pode ser profundamente perturbador desafiar as nossas crenças habituais, fazer estremecer as doutrinas em que aprendemos a confiar" (Sagan 52). Portanto, pode ser que alguns, sentindo o desconforto da dissonância cognitiva gerada pela crítica e pela reflexão se entreguem com mais força e vigor às suas crenças e preconceitos. Tal entrega potencializa o risco da disseminação de desinformação.

Mas isso não deve desanimar a busca por um meio de atenuar os efeitos perniciosos da desinformação nas sociedades. Deve-se considerar que, assim como a internet potencializa a desinformação digital em rede, ela também amplia a possibilidade do acesso ao pensamento do tipo crítico-reflexivo. Pensadores críticos devem empenhar-se, com vigor, não somente na denúncia e no combate - teórico, político, econômico, jurídico - à desinformação generalizada, mas igualmente no desenvolvimento de novas formas de informar e incentivar o questionamento. Precisam ter competência em informação para utilizar os recursos tecnológicos das redes digitais no sentido de fomentar a competência crítica em informação em geral, prioritariamente nas pessoas 
que se encontram mais vulneráveis às armadilhas da desinformação digital em rede. E precisam empenhar-se na defesa da elaboração e implementação de políticas públicas comprometidas com esse fomento.

\section{Referências}

Allcott, Hunt e Matthew Gentzkow. "Social Media and Fake News in the 2016 Election." Journal of Economic Perspectives, vol. 31, no. 2, 2017, pp. 211-236. American Economic Association, doi: dx.doi.org/10.1257/jep.31.2.211.

Aristóteles. "Ética a Nicômaco. "Aristóteles. Nova Cultural, 1996, pp. 117-320. Os Pensadores.

Asch, Solomon E. "Opinions and social pressure." Scientific American, vol. 193, no. 5, 1955, pp. 31-35, www.lucs. Iu.se/wp-content/uploads/2015/02/Asch-1955-Opinions-and-Social-Pressure.pdf. Accessed 12 Ago. 2020.

AVAAZ. "Grupos antivacina já começaram campanha de desinformação contra a vacina do coronavírus: será que isso vai afetar a imunidade de rebanho no Brasil e no mundo?" 2020, https://secure.avaaz.org/campaign/po/desinformacao_vacina_coronavirus/?fbclid=IWAR3Ao7KIZofhoJY9G 78RHKfOQTGoXmNw80C7cbqt3JbLS7gsYQQS8afO10Q. Accessed 22 Aug. 2020.

Bezerra, Arthur Coelho, Marco Schneider e Anna Brisola. "Pensamento Reflexivo e Gosto Informacional: disposição para competência crítica em informação. "Informação \& Sociedade: estudos, vol. 27, no. 1, 2017, pp. 7-16, www.periodicos.ufpb.br/ojs2/index.php/ies/article/view/31114/17408. Accessed 21 Jun. 2019.

Brisola, Anna e Arthur Coelho Bezerra. "Desinformação e Circulação de Fake News: distinções, diagnóstico e reação." Encontro Nacional de Pesquisa em Ciência da Informação - ENANCIB - XIX. Ed. ANCIB.: 2018, pp. 3316-3330, hdl.handle.net/20.500.11959/brapci/102819. Accessed 28 Apr. 2020.

Brito, Vladimir de Paula e Marta Macedo Kerr Pinheiro. "Poder Informacional e Desinformação." Tendências da Pesquisa Brasileira em Ciência da Informação, vol. 8, no. 2, 2015, www.brapci.inf.br/index.php/article/view/0000019439/c3da84b1b4a9f579534c7afefdba4da5. Accessed 26 Feb. 2019.

Capurro, Rafael. "Desafios teóricos y prácticos de la ética intercultural de la información". 2010, www.capurro.de/paraiba.html. Accessed 21 jun. 2019.

Cardoso, Thaís. "Campanha de desinformação sobre vacina contra covid-19 avança com testes no Brasil." 2020, https://sites.usp.br/iearp/campanha-de-desinformacao-sobre-vacina-contra-covid-19-avanca-comtestes-no-brasil/. Accessed 22 Aug. 2020.

Directorate-General for Communications Networks. "A Multi-Dimensional Approach to Disinformation : Report of the Independent High Level Group on Fake News and Online Disinformation." Photo of Publications Office of the European Union, Publications Office of the European Union, 30 Apr. 2018, op.europa.eu/en/publication-detail/-/publication/6ef4df8b-4cea-11e8-be1d-01aa75ed71a1/language-en. Accessed 22 Apr. 2020.

Eagleton, Terry. O Problema dos Desconhecidos: um estudo da ética, Civilização Brasileira, 2010.

Elder, Linda and Richard Paul. "Critical Thinking Development: A Stage Theory." 1996, https://www.criticalthinking.org/resources/articles/ct-development-a-stagetheory.shtm/\#: :text=We\%20make\%20the\%20following\%20assumptions,critical\%20thinker\%2C\%20is\% 20not\%20automatic\%2C. Accessed 12 Aug. 2020. 
Ética Animal. "Raciocínio Motivado e Viés de Confirmação." 2020, https://www.animal-ethics.org/raciociniomotivado-e-vies-de-confirmacao/. Accessed 07 May. 2020.

Fallis, Don. "The Varieties of disinformation." The Philosophy of information quality, edited by Luciano Floridi and Phyllis Illari, Springer, 2014, pp. 135-161.

Freire, Paulo. Educação Como Prática Da Liberdade. 29 ed., Paz e Terra, 2006.

Froehlich, Thomas J. "A not-so-brief account of current information ethics: the ethics of ignorance, missing information, misinformation, disinformation and other forms of deception or incompetence. "Bid: textos universitaris de biblioteconomia i documentación, vol. 12, no. 39, 2017, pp. 1-14, http://bid.ub.edu/pdf/39/en/froehlich.pdf. Accessed 06 Apr. 2020.

Gasque, Kelley Cristine Gonçalves Dias. Letramento Informacional: pesquisa, reflexão e aprendizagem. UnB, 2012, repositorio.unb.br/bitstream/10482/13025/1/LIVRO_Letramento_Informacional.pdf. Accessed 21 Jun. 2019.

Global Disinformation Index Staff. "The Quarter Billion Dollar Question." 2019, disinformationindex.org/wpcontent/uploads/2019/09/GDI_Ad-tech_Report_Screen_AW16.pdf. Accessed 22 Apr. 2020.

Gragnani, Juliana. "Como Comportamento de Manada Permite Manipulação da Opinião Pública por Fakes." BBC Brasil, 2017, www.bbc.com/portuguese/brasil-42243930. Accessed 08 Aug. 2020.

Guzzo, Guilherme Brambatti e Valderez Marina do Rosário Lima. "O Exercício do Pensamento Crítico em Face dos Vieses Cognitivos. " Congresso Ibero-americano de Docência Universitária - CIDU - X. Ed. ediPUCRS.; 2018, pp. 1-12, https://ebooks.pucrs.br/edipucrs/acessolivre/anais/cidu/assets/edicoes/2018/arquivos/233.pdf. Acessed 07 Sep. 2020.

Heller, Agnes. O Cotidiano e a História. 11 ed., Paz e Terra, 2016.

Hogg, Michael A. "Mudança Radical: as Incertezas Globais Ameaçam Nosso Senso de Eu. "Scientific American, vol. 18, no. 201, 2019, pp. 42-45.

Instituto de Estudos Avançados - Polo Ribeirão Preto, Universidade de São Paulo. União Pró-Vacina, 2020. https://sites.usp.br/iearp/uniao-pro-vacina/. Accessed 24 Aug. 2020.

Moreira, Matheus. "Fake news sobre covid-19 produzidas por grupos antivacina saltam 383\%, diz estudo." 2020, https://www1.folha.uol.com.br/equilibrioesaude/2020/08/fake-news-sobre-covid-19-produzida-porgrupos-antivacina-saltam-383-diz-estudo.shtml. Accessed 22 Aug. 2020.

Noelle-Neumann, Elisabeth. A Espiral do Silêncio: opinião pública - nosso tecido social. Estudos Nacionais, 2017.

Olinger, H. N., J. J. Britz e M. S. Olivier. "Western Privacy and Ubuntu: Influences in the Forthcoming Data Privacy Bill." CiteSeerx, 2019,

citeseerx.ist.psu.edu/viewdoc/download?doi=10.1.1.117.3533\&rep=rep1\&type=pdf. Accessed 26 Jun. 2019.

Posetti, Julie e Alice Matthews. "A Short Guide to the History of Fake News and disinformation: a learning module for journalists and journalism educators. "International Center for Journalists, 2018, www.icfj.org/sites/default/files/2018-

07/A\%20Short\%20Guide\%20to\%20History\%20of\%20Fake\%20News\%20and\%20Disinformation_ICFJ\%2 OFinal.pdf. Accessed 03 Aug. 2020. 
Rodrigues, Aroldo. Da Inutilidade das discussões: uma perspectiva psicológica. 2018.

Sagan, Carl. O Mundo Assombrado pelos Demônios: a ciência vista como uma vela no escuro. Companhia das Letras, 2006.

Santo Agostinho. A Mentira - Contra a Mentira. Paulus, 2019. Patrística.

Schneider, Marco. "CCI/7: Competência Crítica em Informação (em 7 níveis) como dispositivo de combate à pós-verdade." iKritica: Estudos Críticos em Informação. Garamond, 2019, pp. 73-116.

Seth, Anil K. "Nossos Universos Interiores: a realidade é construída pelo cérebro, e não existem dois cérebros exatamente iguais." Scientific American, vol. 18, no. 201, 2019, pp. 27-33.

Van Bavel, Jay J. e Andrea Pereira. "The Partisan Brain: an identity-based model of political belief." Trends in Cognitive Sciences, vol. 22, no. 3, 2018, pp. 213-224. Elsevier BV, doi: dx.doi.org/10.1016/j.tics.2018.01.004.

Wardle, Claire e Hossein Derakshan. "Information disorder: toward an interdisciplinary framework for research and policy making." Council of Europe, 2017. https://rm.coe.int/information-disorder-toward-aninterdisciplinary-framework-for-researc/168076277c. Accessed 15 Aug. 2020.

Wardle, Claire. "Information disorder: the essential glossary." Havard Kennedy School - Shorestein Center on media, Politics and Public Policy, 2018. https://firstdraftnews.org/wpcontent/uploads/2018/07/infoDisorder_glossary.pdf?x20994. Accessed 06 May 2020.

Wardle, Claire. "Uma Nova Desordem Mundial: nossa tendência a compartilhar conteúdo sem refletir é usada para disseminar desinformação." Scientific American, vol. 18, no. 201, 2019, pp. 46-51.

W/Brasil. "Hitler." Folha de São Paulo, 1987, 1:02. Disponível em: https://www. youtube.com/watch?v=pY4FCKIQISA. 